\title{
EXPERIENCES AND PRACTICES IN MODELING DISTANCE LEARNING CURRICULA FOR CAPILLARY APPROACHES AND LIMITED ICT RESOURCE SCENARIOS
}

\author{
Martins, Joberto S. B. and Quadros, Teresinha \\ University Salvador - UNIFACS Salvador - Bahia - Brazil \\ joberto@unifacs.br ; t.quadros@terra.com.br www.unifacs.br
}

\begin{abstract}
Actual curricula design and development for distance learning courses have been challenged by constraints such as the absence of conventional face-toface (F2F) (Keeton 2002) class communication, the required student's autonomy and the need for ergonometric interfaces, just to mention some. In general, both the extensive use and the focused application of ICT components (Felder \& Silverman 1988) may provide some significant contributions to overcome these drawbacks. The objective of this paper is to describe a distance learning curricula design and implementation strategy considering a capillary approach with limited ICT resources. It highlights the approaches undertaken and the obtained results. The implementation scenario is an undergraduate level course for active high-school teachers requiring certification for improving their pedagogical methods. The numbers, methods and implementation aspects presented are based on a real-life ongoing course.
\end{abstract}

Key words: Curricula design and structure, ICT resources and constraints, capillary approach.

\section{CURRICULA IMPLEMENTATION CHALLENGES - THE SCENARIO}

Actual curricula design and development for distance learning courses have been challenged by constraints such as the absence of conventional face-to-face (F2F) (Keeton 2002) class communication, the required student's autonomy, active participation and highly interactive engagement, 
the need for ergonometric interfaces, just to mention some. In this context, both the extensive use and the focused application of ICT components (Felder \& Silverman 1988) may provide some significant contributions to overcome these drawbacks, typically existent in distance learning conventional approaches.

The real-life learning challenge effectively discussed in this paper consists in providing high quality education services and finding scalable solutions constrained by ICT limited resources (limited bandwidth telecommunication resources, limitation in computer capacity, others). This scenario will typically happen when a capillary approach, not restricted to main urban centers and densely digitalized areas, is considered. Beyond that, lecturers and students profiles are such that, for instance, familiarity with computers and the cognitive learning paradigm are not completely developed and, as such, have to be packaged in the course methodology itself.

The targets are undergraduate level courses in diverse knowledge areas. The basic approach discussed is focused on modeling curricula development by using interdisciplinary learning (Martins et al. 2002) and fully computerassisted pedagogical, collaborative and self-learning approaches.

\section{THE DESIGN PRINCIPLES}

The design principles adopted in the curricula design are the capillary approach, the adoption of a web-centric solution as the basis for the mediating process and a highly flexible implementation approach which corresponds to an intensive use of multimedia, ICT resources and multiple content formats.

The capillary approach is intended to provide higher education services in rural areas, underdeveloped regions and other unassisted remote locations where they are scarce and have limited options. By adopting this principle, attendees do not need to move away form their home locations and, beyond that, they may keep their activities while following courses.

The web-centric option is due to its intrinsic characteristics such as, a high capillary and modern solution with worldwide presence, its ability to ergonomically integrated different media types which are fundamental for the distance learning process and, finally, its support to human interaction and mediation processes. These characteristics are valuable assets to overcome the classical problems found in distance learning courses such as student isolation and the difficulties found in providing a more personalized follow-up.

Delivering contents in multiple medias and multiple formats is one of the most important design principles followed by the curricula modeling process 
(Figure 1). In effect, the flexible implementation approach is such that courses are created with multiple media formats and intensive use of ICT resources. In addition, the course logistics are adapted to the socioeconomics of the target public and region and, as such, the technological infrastructure available has to be taken in account.

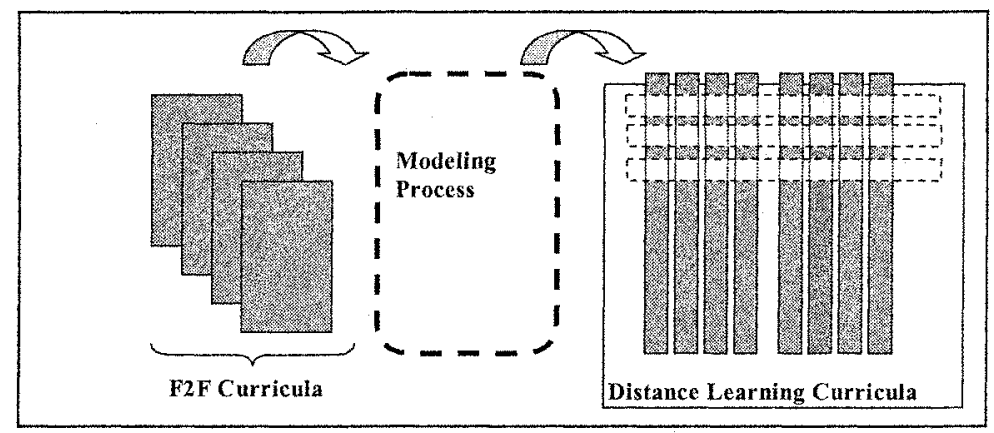

Figure 1. Distance learning curricula adaptation process

In summary, the discussed approach to develop distance learning curricula needs an adaptation process that is dependable on ICT resources available, considers the capillary approach and is dependable of curricula content specific constraints. Additional guidelines for curricula development are provided by the pedagogical model adopted.

\section{THE PEDAGOGICAL MODEL}

The pedagogical model adopted for curricula development preserves the design principles discussed and, in addition, is based on principles such as autonomous cognitive learning process, interdisciplinary methods, collaborative and meaningful learning.

By adopting an autonomous cognitive learning process as one of the pedagogical model principles, the curricula, through its pedagogical practices, stimulates the student autonomy and contributes to overcoming the isolation typically found in distance learning courses. The systematic research activities realized using networked communication tools, the huge amount of information available with instant access and the friendly web interfaces contribute to the development of the autonomous cognitive posture of learners. 
The interdisciplinary learning method is achieved by having disciplines grouped in knowledge areas and having a curricula managing system that articulates knowledge when executing the disciplines.

Collaborative learning means to explore systematically within curricula the interaction among students by using the virtual tools provided by information and communication technologies. The web-centric approach is particularly helpful for this purpose. By this principle, experience sharing is instigated, the collaborative and interdisciplinary work is stimulated and the learners' autonomy is developed.

Meaningful learning is a pedagogical principle in which applied learning materials use learner's experience as an asset. The daily experience of each one is used as the point of departure and continuous reference for the learning process.

The proposed pedagogical model defines a curricula structure implementation (Figure 2) based on "learning core unities" which are grouped in "thematic matrixes" and distributed in temporal units called "flows". The "disciplines/ modules" respond to the learning process itself and are grouped in cores units, thematic matrixes and flows (temporal arrangement). They correspond to the skills and competences to be developed during each step of the construction process leading to the professional profile expected.

The pedagogical model establishes that all curricula have an "integration matrix" in its structure that has its focus on practices and evaluation. As the name suggests, its objective is to integrate the course contents developed by the disciplines in a flow by using an interdisciplinary approach and the student's experience as reference. The integration matrix is the effective way to assure the pedagogical principles defined (interdisciplinary, collaborative work, autonomy and meaningful learning).

In summary, the adopted design model is based on a collaborative pedagogy, reinforces the idea of actors cooperation in the pedagogical process, considers the knowledge exchange as part of the learning process and integrates the lecturer in the learning community (Vygotsky 1984) (Wallon 1982). 
for Capillary Approaches and Limited ICT Resource Scenarios

\begin{tabular}{|c|c|c|c|c|c|c|}
\hline$\underset{1}{M \text { atrix }}$ & $\begin{array}{c}M \text { atrix } \\
2\end{array}$ & $\begin{array}{c}\text { Matrix } \\
3\end{array}$ & $\underset{4}{M \text { atrix }}$ & $\begin{array}{c}\text { Matrix } \\
5\end{array}$ & Flow & \\
\hline $\begin{array}{c}\text { Module } \\
1\end{array}$ & $\begin{array}{c}\text { Module } \\
1\end{array}$ & & $\underset{1}{\text { Module }}$ & $\begin{array}{c}\text { Module } \\
1\end{array}$ & Flow 1 & \multirow{2}{*}{$\begin{array}{c}\text { Core } \\
1\end{array}$} \\
\hline $\begin{array}{c}\text { Module } \\
2\end{array}$ & $\underset{2}{M o d u l e}$ & & $\begin{array}{c}\text { Module } \\
2\end{array}$ & $\begin{array}{c}\text { Module } \\
2\end{array}$ & Flow 2 & \\
\hline $\begin{array}{c}\text { Module } \\
3\end{array}$ & $\begin{array}{c}\text { Module } \\
3\end{array}$ & $\begin{array}{c}\text { Module } \\
1\end{array}$ & & $\begin{array}{c}\text { Module } \\
3\end{array}$ & Flow 3 & \multirow{3}{*}{$\underset{2}{\operatorname{Core}}$} \\
\hline & $\begin{array}{c}\text { Module } \\
4\end{array}$ & $\underset{2}{M o d u l e}$ & & $\underset{4}{M o d u l e}$ & Flow 4 & \\
\hline & & $\begin{array}{c}\text { Module } \\
3\end{array}$ & $\begin{array}{c}\text { Module } \\
3\end{array}$ & $\begin{array}{c}\text { Module } \\
5\end{array}$ & Flow 5 & \\
\hline & & $\underset{4}{\operatorname{Module}}$ & $\underset{4}{\text { Module }}$ & $\underset{6}{M o d u l e}$ & Flow 6 & \multirow{2}{*}{$\begin{array}{c}\text { Core } \\
3\end{array}$} \\
\hline & & & & $\underset{7}{M a d u l e}$ & Flow 7 & \\
\hline
\end{tabular}

Figure 2. Curricula structure

The curricula structure by itself does not guarantees the principles proposed for the pedagogical model and effectively corresponds to an implementation plan and reference for the pedagogical practices. The curricula execution has to guarantee consistent practices such as professors developing interdisciplinary contents, tutors being able to act as mediators and, in addition, the adequacy of the technological infra-structure should support the necessary interactive level.

\section{PRACTICES, METHODS AND EXPERIENCE}

The discussed design principles, pedagogical model and curricula development are in practice intended to support real-life, limited ICT resources and high capillary scenarios. In effect, a broad coverage (Portuguese speaking countries like Brazil, Portugal, Angola, others) and a significant numbers of students (thousands) are the course targets. A pilot project as described is the experimental basis for analysis and discussion:

- Undergraduate course: Portuguese and English Language (2.940 hours -03 years).

- Course coverage: state of Bahia (Brazil), 198 provinces (about 2.000 $\mathrm{Km}$ range), most of them with very difficult terrestrial access and very limited ICT and computational facilities.

- Attendees profile: 500 students, most of them beyond 40 years, active lectures on various teaching subjects, having very limited computer abilities. 


\subsection{ICT media choices and infra-structure}

The course implementation scenarios are restrictive with respect to ICT resources and have to be considered case-by-case by indicating the media options and compatible procedures. The proposal is to have a web-centric approach coupled with a rich set of ICT media facilities that could be adapted to real-life and capillary restrictive scenarios.

The basic media choices and ICT facilities adopted for all curricula to be implemented are:

- The platform: TELEDUC, an open-source web-based distance learning supporting tool;

- Synchronous tools: chat, video-conferencing (dedicated network), web-based conferencing and free callback service $(0800)$;

- Asynchronous tools: forum, electronic mail, broadcasting conferences, mail (postal service) and faxing;

- Contents distribution options: web distribution, printed material, multimedia CD (web content copy for off-line access).

The platform has characteristics and features such as security mechanisms, student follow-up tools, interactive mechanisms, ergonomic interfaces, and intuitive navigation, among others.

The synchronous and asynchronous tools should support the interactive processes in different circumstances in terms of the available ICT resources and student's time availability to follow the course. Asynchronous tools are the predominant option for most of the implemented courses $(90 \%$ asynchronous $-10 \%$ synchronous).

The complete set of media options and communication facilities considered for all courses are indicated in Figure 3.

\subsection{Capillary and ICT Constraints Mappings}

The constraints applied to the basic implementation setup (set of medias and communication facilities) are related respectively to the student profile, the network access facilities and the computer equipment available.

An attendee is considered to be qualified to follow a distance learning course if he has minimum computer handling abilities (basic informatics concepts: commands, peripheral manipulation, others) and, beyond that, he has minimum understanding of the autonomy, self-learning and other characteristics necessary to undertake a distance learning program.

A minimalist acceptable condition for network access corresponds to having either permanent or dialup access independently of their quality. Dialup access is low-speed and, as such, is a permanent restriction for multimedia and lucidity facilities incorporated in web pages (course 
material). Additionally, connectivity may be "occasional". Connectivity is considered occasional when it represents a financial cost for the attendee (access is paid and attendees income is predominantly low-level) and/or the connection has very low quality. In effect, strong ICT restrictions do exist for the majority of cities and provinces covered by the course. As an example, dialup connections are typically $33 \mathrm{Kbps}$ and the "high-speed" ADSL connections (256Kbps) availability is rare.

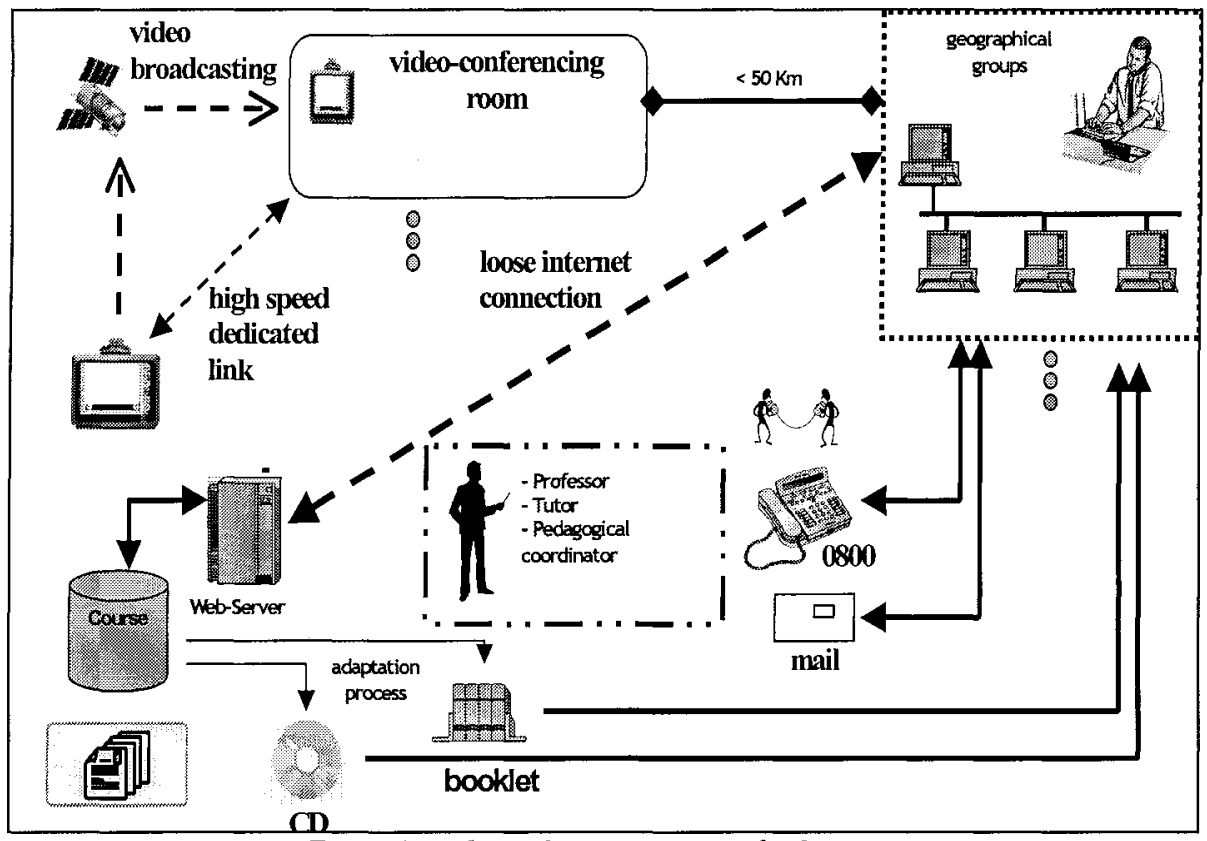

Figure 3.Media and communication facilities

Minimum quality computers are those available and capable of running multimedia applications. Unavailability condition corresponds to a situation where the computer is effectively unavailable and/or has unacceptable lowperformance.

As such, the potentially available mappings that have to be considered in a large-scale implementation are as follows:

1. Case " $A$ " corresponds to a potentially qualified distance learning scenario. There is a minimum quality computer, the network access is available and attendees profiles are satisfactory. We have then a potential online student.

2. Case " $B$ " corresponds to a less qualified attendee situation where computers are available but there is no satisfactory network access 
and/or attendees do not have the necessary abilities to follow a distance learning program.

3. Case " $\mathrm{C}$ " is a worst-case situation where computers are unavailable and, beyond that, combinations of network access and attendees abilities unavailability are present.

The target is to promote distance learning in all the above scenarios and provide the practices methods, adaptation approaches and strategies in order to achieve a high quality course.

\subsection{Practice Methods and Pedagogical Strategies}

The described constraints mappings " $\mathrm{B}$ " and " $\mathrm{C}$ " are the focus of the practices methods and pedagogical strategies defined to deal with the challenges resulting from a capillary approach and they do represent a reallife implementation issue.

The main guidelines and practices followed in order to overcome the restrictions imposed are:

- To provide attendees with computer skills training and introduce distance learning working principles as part of the course package itself;

- To always adopt a consistent and integrated set of flexible multiple media content distribution (course material);

- To guarantee multiple redundant interaction channels between the professor, tutors and students.

The reason to include the teaching of computer skills (digital insertion) and introduce distance learning working principles as part of the course itself has strategic and economical reasons. The adoption of this approach allows an immediate increase of the potential number of attendees in rural areas and underdeveloped economic regions and, as such, is fundamental for a capillary approach. Certainly, this argument is not valid worldwide and, eventually, would be applied only for underdeveloped and $3^{\text {rd }}$ world countries.

The distribution of the course content by multiple media (web server, booklet - printed material and CD) requires an integrated approach. The web server content distribution is focused on scenarios where connectivity is satisfactory. The CD and printed material have a dual purpose:

- For scenarios with satisfactory connectivity, they just complement the web content distribution mechanism.

- For scenarios where web connectivity is compromised, both the $\mathrm{CD}$ and printed material are the content distribution mechanism itself.

This dual approach requires from the pedagogical point of view a certain care in the sense that each media requires a specific language and different 
evaluation methods. Due to that, students moving their condition (online to offline and vice-versa) do require specific and extra attention from professor and tutors in terms of the pedagogical model.

The guarantee of multiple interaction communication and feedback channels has multiple purposes. A key factor for the course quality and success is the promotion of the interaction, collaboration, student autonomy and assistance (tutors and professor). This is achieved by two different mechanisms.

The first mechanism corresponds to the course contents and activities being structured on the different media types and the second fundamental mechanism corresponds to the mediation action promoted by professor and tutors with respect to student's interaction.

In this sense, the use of postal service, callback, and faxing as the student feedback channel should be considered as complementary and temporary resources. They should be used only for a limited period to overcome the ICT resource limitations.

In terms of the pedagogical strategies that should be adopted we have:

a The intensification of the tutorial action using telephony services and video-conferencing resources complemented with ICT supported interaction by fax and call-back service;

- The stimulus for group leadership among students in order to promote experiences sharing and reduce the isolation resulting from the limited ICT resources;

- An increase in the amount of face-to-face meetings with respect to those previewed in case " $\mathrm{A}$ " scenario;

- The guarantee of prompt feedback to students in terms of their activities results and evaluation.

Although discussed in this paper as isolated practices or strategies, all the discussed guidelines are grouped in a broader planning document denominated "fidelity plan". The fidelity plan is targeted to guarantee overall course quality and, as far as the pedagogical and technological solutions are concerned, it consolidates a list of integrated case-by-case solutions according with the implementation scenario considered.

\subsection{Course Quality as an Consolidation Approach}

Course evaluation is a key quality factor and, as such, the fidelity plan defines the evaluation procedures, the quality metrics, the relation among pedagogical and practical actions for distinct scenarios, the timing constraints involved when upgrading attendees and, finally, computes a "quality rank". 
The discussion about the fidelity plan details is beyond the scope of this paper and, in terms of the practice methods, technological solutions and pedagogical strategies discussed, it just organizes them. This is realized by scenario (cases " $A$ ", " $B$ " and " $C$ ") and an upgrade time schedule (case " $C$ " $\rightarrow$ " $\mathrm{B}$ " $\rightarrow$ " $\mathrm{A}$ ") is defined. The ability to accomplish the defined schedule is one of the metrics contributing to the overall course quality rank. Figure 4 illustrates a set of typical time constraints as defined for a course having part of its attendees being upgraded among levels.

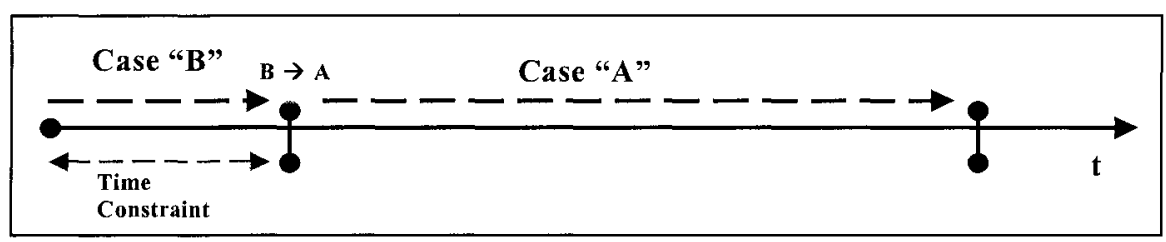

Figure 4. General schedule for upgrading attendees

The fidelity plan overall objectives are, firstly, to keep attendees satisfied by evaluating the course and providing feedbacks in order to achieve the best possible course quality (quality verification and assurance) and, secondly, to bring in a pre-defined time-schedule at least $90 \%$ of all attendees to the fully qualified implementation scenario (case "A").

In other words, one objective of the flexible and adaptable approach being used is, on route, to provide an "upgrade" in terms of necessary attendees background and to point out and propose alternative solutions for the limited computational resources.

The basic set of premises behind the flexible and adaptable pedagogical and technological solutions proposed are:

口 ICT limitations should not interfere on course quality results;

- Transition between scenarios are "transparent" to course execution; and

- Transition between scenarios occurs at specific and pre-defined time frames.

\section{CONCLUSIONS AND CONSIDERATIONS}

The design principles, implementation issues and practices adopted for a real-life distance learning course considering a capillary approach and limited ICT resources have been briefly described.

It is argued that for a huge volume of attendees spread over less developed areas, a highly flexible and adaptable set of practices have to be applied. The general issues to consider consist in, firstly, to overcome the classical problems faced by distance learning curricula (autonomy, 
interactions, other) and, additionally, to articulate the pedagogical practices in order to deal with different student's profiles and execution scenarios. The pedagogical model proposed, the multiple media tools and content distribution mechanisms, the mapping of the existent constraints and associated pedagogical strategies to handle deficiencies are, all together, an alternative to pursue good quality course results. It is also argued that a high quality course objective may be achieved by having specific actions to "upgrade" student's abilities and overcome permanent ICT resources restrictions.

\section{REFERENCES}

Decina, M. and Trecordi, V. (1997) Convergence of Telecommunications and Computing to Network Models for Integrated Services and Applications. Proceedings of the IEEE. Special Edition - The Global Information Infraestructure. pp. 1887-1914.

Felder, R. M. and Silverman, L. K. (1988) Learning and Teaching Styles in Enginecring Education. Engineering Education, $n^{\circ} 78$, Vol.7, pp. $674-681$.

Keeton, M. Sheckley, B. and Krejci-Griggs (2002), J. Effectiveness and Efficiency in Higher Education for Adults. Council on Adult and Experimental Learning. Chicago: KendallHunt.

Martins, J. S. B. et alli. (2002) Interdisciplinary and Flexible Curricula Practices in Electric and Telecommunications Engineering - A Case Study, IFIP Working Group 3.2 Conference - Informatics and ICT in Higher Education -- ICTEM 2002.

Vygotsky, L. S. (1984), A formação social da mente. São Paulo: Martins Fontes.

Wallon, Henri. (1982), La vie mentale. Paris: Éditions Sociales. 